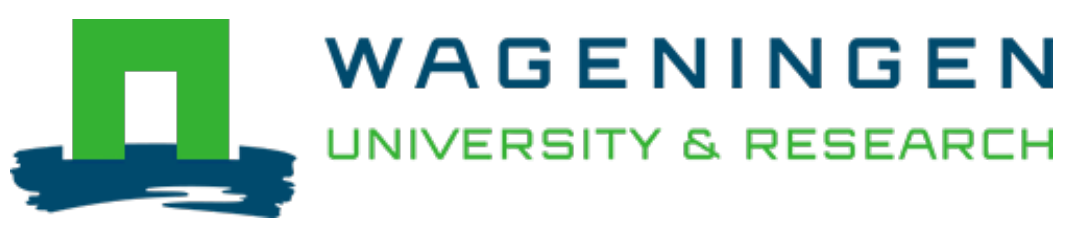

\author{
Influence of Lactobacillus plantarum WCFS1 on post-acidification, metabolite \\ formation and survival of starter bacteria in set-yoghurt \\ Food Microbiology \\ Settachaimongkon, Sarn; Valenberg, Hein J.F.; Gazi, Inge; Nout, M.J.R.; Hooijdonk, Toon C.M. et al \\ https://doi.org/10.1016/j.fm.2016.04.008
}

This publication is made publicly available in the institutional repository of Wageningen University and Research, under the terms of article $25 \mathrm{fa}$ of the Dutch Copyright Act, also known as the Amendment Taverne. This has been done with explicit consent by the author.

Article 25 fa states that the author of a short scientific work funded either wholly or partially by Dutch public funds is entitled to make that work publicly available for no consideration following a reasonable period of time after the work was first published, provided that clear reference is made to the source of the first publication of the work.

This publication is distributed under The Association of Universities in the Netherlands (VSNU) 'Article $25 \mathrm{fa}$ implementation' project. In this project research outputs of researchers employed by Dutch Universities that comply with the legal requirements of Article $25 \mathrm{fa}$ of the Dutch Copyright Act are distributed online and free of cost or other barriers in institutional repositories. Research outputs are distributed six months after their first online publication in the original published version and with proper attribution to the source of the original publication.

You are permitted to download and use the publication for personal purposes. All rights remain with the author(s) and / or copyright owner(s) of this work. Any use of the publication or parts of it other than authorised under article $25 \mathrm{fa}$ of the Dutch Copyright act is prohibited. Wageningen University \& Research and the author(s) of this publication shall not be held responsible or liable for any damages resulting from your (re)use of this publication.

For questions regarding the public availability of this publication please contact openscience.library@wur.nl 


\title{
Influence of Lactobacillus plantarum WCFS1 on post-acidification, metabolite formation and survival of starter bacteria in set-yoghurt
}

\author{
Sarn Settachaimongkon ${ }^{\text {a, b }}$, Hein J.F. van Valenberg ${ }^{c}$, Inge Gazi ${ }^{c}$, M.J. Robert Nout ${ }^{\text {d }}$, \\ Toon C.M. van Hooijdonk ${ }^{\mathrm{c}}$, Marcel H. Zwietering ${ }^{\mathrm{d}}$, Eddy J. Smid ${ }^{\mathrm{d}, *}$ \\ a Department of Food Technology, Faculty of Science, Chulalongkorn University, Bangkok 10330, Thailand \\ b Omics Sciences and Bioinformatics Center, Faculty of Science, Chulalongkorn University, Bangkok 10330, Thailand \\ ${ }^{c}$ Dairy Science and Technology Group, Chair of Food Quality and Design, Wageningen University, P.O. Box 17, 6700 AA Wageningen, The Netherlands \\ d Laboratory of Food Microbiology, Wageningen University, P.O. Box 17, 6700 AA Wageningen, The Netherlands
}

\section{A R T I C L E I N F O}

\section{Article history:}

Received 22 February 2016

Accepted 26 April 2016

Available online 28 April 2016

\section{Keywords:}

Dairy

Fermented milk

Lactic acid bacteria

Probiotics

Stress response

Metabolomics

\begin{abstract}
A B S T R A C T
The objectives of this study were to evaluate the growth and survival of the model probiotic strain Lactobacillus plantarum WCFS1 in co-culture with traditional yoghurt starters and to investigate the impact of preculturing on their survival and metabolite formation in set-yoghurt. L. plantarum WCFS1 was precultured under sublethal stress conditions (combinations of elevated $\mathrm{NaCl}$ and low $\mathrm{pH}$ ) in a batch fermentor before inoculation in milk. Adaptive responses of L. plantarum WCFS1 were evaluated by monitoring bacterial population dynamics, milk acidification and changes in volatile and non-volatile metabolite profiles of set-yoghurt. The results demonstrated that sublethal preculturing did not significantly affect survival of $L$. plantarum WCFS1. On the other hand, incorporation of sublethally precultured L. plantarum WCFS1 significantly impaired the survival of Lactobacillus delbrueckii subsp. bulgaricus which consequently reduced the post-acidification of yoghurt during refrigerated storage. A complementary metabolomics approach using headspace SPME-GC/MS and ${ }^{1} \mathrm{H}$ NMR combined with multivariate statistical analysis revealed substantial impact of sublethally precultured $L$. plantarum WCFS1 on the metabolite profiles of set-yoghurt. This study provides insight in the technological implications of nondairy model probiotic strain L. plantarum WCFS1, such as its good stability in fermented milk and the inhibitory effect on post-acidification.
\end{abstract}

๑) 2016 Elsevier Ltd. All rights reserved.

\section{Introduction}

Functional yoghurt variants have been produced by incorporating bacterial strains called "probiotics" which are defined as live microorganisms which when administered in adequate amounts confer a health benefit on the host (FAO/WHO, 2002). Probiotics have been widely employed as adjunct cultures in the production of fermented dairy products (Vasiljevic and Shah, 2008). Most commercial probiotics incorporated in yoghurt are strains belonging to the genera Lactobacillus and Bifidobacterium (Lourens-Hattingh and Viljoen, 2001) of which functional and technological attributes have been extensively documented (Vasiljevic and Shah, 2008).

Lactobacillus plantarum is a versatile facultative heterofermentative lactic acid bacterium (LAB) present in plant-based

\footnotetext{
* Corresponding author

E-mail address: eddy.smid@wur.nl (E.J. Smid).
}

fermented foods as well as meat, fish and dairy products (de Vries et al., 2006; Siezen et al., 2010). L. plantarum is also encountered as a natural inhabitant of the human gastrointestinal tract with identified candidate probiotic genes and potential healthassociated properties (de Vries et al., 2006; Kleerebezem et al., 2003; Siezen et al., 2012). A variety of $L$. plantarum strains, e.g. $299 \mathrm{v}$ and Lp01, have been commercialized in the probiotic marketplace (de Vries et al., 2006; Shah, 2007). Advances in “ omics" technologies were instrumental in making L. plantarum WCFS1 one of the primary model organisms in LAB research (Siezen and van Hylckama Vlieg, 2011). The complete genome sequence of $L$. plantarum WCFS1, a single colony isolate of L. plantarum NCIMB 8826 from human saliva, has been published (Kleerebezem et al., 2003; Siezen et al., 2012). This has provided insight in the potential probiotic properties including adhesionencoding genes as well as several genetic loci involved in the immunomodulation capacity of this strain (Bron et al., 2012; Kleerebezem et al., 2003). In addition, functional-genomics 
studies have extensively provided new information on how L. plantarum responds to various environmental stresses from a molecular perspective (Bron et al., 2012; Ricciardi et al., 2012). Nevertheless, the information regarding the relation between metabolomics profiling and technological aspects of applying L. plantarum strains in a dairy-based environment such as fermented milk is rather limited (de Bok et al., 2011; Georgieva et al., 2009; Mirlohi et al., 2014; Piras et al., 2013).

It is recommended that a probiotic product should contain at least $10^{6} \mathrm{CFU} / \mathrm{g}$ of viable probiotic cells throughout the entire shelflife for ensuring their health-promoting effects (Vasiljevic and Shah, 2008). However, many probiotic strains exhibit a low capacity to grow in milk during fermentation and are not able to survive well in fermented milk during refrigerated storage (Gueimonde et al., 2004). One of the strategies to improve the viability of probiotics is stress adaptation which can be performed by pretreating (preculturing) probiotic cells under sublethal stress conditions prior to exposure to a more harsh environment (Upadrasta et al., 2011). A previous study by the authors focusing on two commercial probiotic strains, i.e. Lactobacillus rhamnosus GG and Bifidobacterium animalis subsp. lactis BB12, demonstrated that this approach allows probiotic cells to develop adaptive responses leading to a significant increase in their survival in set-yoghurt (Settachaimongkon et al., 2015). Furthermore, a complementary metabolomics approach using headspace SPME-GC/MS and ${ }^{1} \mathrm{H}$ NMR successfully revealed a substantial impact on the metabolic activity of yoghurt starters and probiotics demonstrated by distinctive volatile and non-volatile polar metabolite profiles of the fermented products (Settachaimongkon et al., 2014a, 2014b, 2015). This information is technologically relevant since metabolic responses of stress-adapted probiotics may substantially affect the biochemical and organoleptic characteristics of the product (Serrazanetti et al., 2009).

The objectives of this study were to evaluate the growth and survival of potential probiotic L. plantarum WCFS1 in co-culture with traditional yoghurt starters and to investigate the impact of preculturing under sublethal stress conditions (combinations of elevated $\mathrm{NaCl}$ and low $\mathrm{pH}$ ) on its survival and metabolite formation in set-yoghurt. Changes in bacterial population dynamics and extent of milk acidification were monitored during fermentation and refrigerated storage. Biochemical changes associated with bacterial metabolism were characterized by a metabolomics approach using headspace SPME-GC/MS and ${ }^{1} \mathrm{H}$ NMR technique. Finally, volatile and non-volatile polar metabolite profiles of yoghurt samples were statistically compared using multivariate analysis.

\section{Materials and methods}

\subsection{Yoghurt starters and potential probiotic strain}

Frozen direct-vat-inoculation pellets of Streptococcus thermophilus C44 and Lactobacillus delbrueckii subsp. bulgaricus C49 (CSK Food Enrichment, Ede, the Netherlands) were transferred to ambient temperature $\left(20 \pm 3^{\circ} \mathrm{C}\right)$ for $15 \mathrm{~min}$ before use. A culture of L. plantarum WCFS1 (LP-WCFS1) obtained from NIZO food research (Ede, the Netherlands) was propagated in our laboratory and stored as a $20 \%(\mathrm{v} / \mathrm{v})$ glycerol stock-culture at $-80{ }^{\circ} \mathrm{C}$. Before use, the frozen LP-WCFS1 culture was re-propagated in MRS broth $(1 \%(\mathrm{v} / \mathrm{v})$ inoculation) (Merck, Darmstadt, Germany) at $37{ }^{\circ} \mathrm{C}$ for $24 \mathrm{~h}$ under anaerobic condition (Anoxomat ${ }^{\mathrm{TM}}-\mathrm{Mart}^{\mathbb{R}}$, Drachten, the Netherlands). Then, the cells were collected, washed and resuspended in milk to obtain a cell density of approximately $10^{8} \mathrm{CFU} / \mathrm{g}$ as described previously (Settachaimongkon et al., 2015). This culture was defined as control group, i.e. standard precultured LP-
WCFS1.

\subsection{Preculturing of L. plantarum WCFS1 under sublethal stress conditions}

\subsubsection{Screening for sublethal stress conditions}

Suitable sublethal stress conditions, elevated $\mathrm{NaCl}$ concentration and low pH, for LP-WCFS1 were preliminary determined according to the method described by Settachaimongkon et al. (2015). The concentrations of $\mathrm{NaCl}$ which caused 0.5 and $1.0 \mathrm{log}$ reduction of viable cells compared to those enumerated in unsalted MRS broth after anaerobic incubation at $37^{\circ} \mathrm{C}$ for $24 \mathrm{~h}$ (data not shown) were determined as low and high sublethal $\mathrm{NaCl}$ levels, i.e. $1.5 \%$ and $4.5 \%(\mathrm{w} / \mathrm{v})$, respectively. On the other hand, sublethal $\mathrm{pH}$ levels were assigned at $1.0 \mathrm{pH}$ unit above and below the optimum pH for the growth of LP-WCFS1, i.e. pH 4.5 and 6.5. The combinations of sublethal $\mathrm{NaCl}-\mathrm{pH}$ treatments were finally organized as a $2 \times 2$ between subjects factorial design (Table 1).

\subsubsection{Preculturing of $L$. plantarum WCFS1 in a batch fermentor}

Preculturing of LP-WCFS1 was conducted in a $750 \mathrm{~mL}$ Multifors2 Bacterial System Bioreactor fully operated by IRIS-V.5.3 control software (Infors HT, Bottmingen, Switzerland). The preculturing conditions were adjusted and automatically maintained at a desired pre-set values $\left(37^{\circ} \mathrm{C}\right.$; a combination of elevated $\mathrm{NaCl}$ and low $\mathrm{pH}$ ) as previously described (Settachaimongkon et al., 2015). After $24 \mathrm{~h}$ (cells in stationary phase monitored by optical density; data not shown), sublethally precultured LP-WCFS1 cells were collected, washed and resuspended in milk before use. These steps were performed to avoid carryover effects of chemicals and nutrients from the preculturing medium which may significantly influence the metabolomics data derived from ${ }^{1} \mathrm{H}$ NMR analysis (Settachaimongkon et al., 2015). Sublethally precultured LP-WCFS1 was subsequently inoculated in co-cultures with traditional yoghurt starters as described previously (Settachaimongkon et al., 2015). The preculturing was performed in three batches for each stress combination.

\subsection{Set-yoghurt fermentation}

Reconstituted Nilac skimmed milk (NIZO food research, Ede, the Netherlands) was prepared according to the method previously described (Settachaimongkon et al., 2014a). The pasteurized milk was inoculated with co-cultures of yoghurt starters and different types of LP-WCFS1, i.e. standard precultured (control) and four types of sublethally precultured cells. The initial inoculum of the two yoghurt starter bacteria and LP-WCFS1 were adjusted respectively at $10^{6} \mathrm{CFU} / \mathrm{g}$ (ratio $1: 1: 1$ ). After inoculation, set-yoghurt fermentation and sample collection were carried out according to the methods previously described (Settachaimongkon et al., 2014b). The fermentation was performed in three replicates for each type of starter combination.

Table 1

Sublethal stress conditions (combination of elevated salt and low $\mathrm{pH}$ ) modified in MRS broth for preculturing of $L$. plantarum WCFS1 under a well-controlled batch scale fermentor.

\begin{tabular}{lll}
\hline Salt stress & Acid stress & \\
\cline { 2 - 3 } & Low pH & Neutral pH \\
\hline Low \%NaCl & $1.5 \% \mathrm{NaCl}-\mathrm{pH} 4.5$ & $1.5 \% \mathrm{NaCl}-\mathrm{pH} 6.5$ \\
High \% NaCl & $4.5 \% \mathrm{NaCl}-\mathrm{pH} 4.5$ & $4.5 \% \mathrm{NaCl}-\mathrm{pH} 6.5$ \\
\hline
\end{tabular}




\subsection{Enumeration of viable bacteria}

Viable counts of $S$. thermophilus were determined as previously described (Settachaimongkon et al., 2014a). Viable counts of L. delbrueckii subsp. bulgaricus were determined on MRS agar $\mathrm{pH}$ 5.7 (Merck, Darmstadt, Germany) after anaerobic incubation (Anoxomat ${ }^{\mathrm{TM}}$-Mart ${ }^{\circledR}$, Drachten, the Netherlands) at $45^{\circ} \mathrm{C}$ for $72 \mathrm{~h}$ (selectivity tested in this study). Viable counts of LP-WCFS1 were determined on MRS agar $\mathrm{pH} 5.7$ supplemented with $50 \mathrm{mg} / \mathrm{L}$ vancomycin (Merck, Darmstadt, Germany) after anaerobic incubation at $37{ }^{\circ} \mathrm{C}$ for $24 \mathrm{~h}$ (modified from Saccaro et al. (2011)).

\subsection{Determination of acidification profile}

Production of acid during set-yoghurt fermentation and storage was expressed by changes in $\mathrm{pH}$ and increases in titratable acidity as described previously (Settachaimongkon et al., 2014a).

\subsection{Analysis of volatile metabolites by headspace SPME-GC/MS}

A model scenario of set-yoghurt fermentation was carried out directly in GC vials (Settachaimongkon et al., 2014a). The fermentation was performed in three replicates for each type of starter combination. Extraction and determination of volatile compounds by headspace SPME-GC/MS were performed according to the method previously described (Settachaimongkon et al., 2014a). Volatile metabolites were identified using AMDIS software (NIST, Gaithersburg, MD, USA) referred to NIST/EPA/NIH database and an in-house library (Hettinga et al., 2009). Specific retention time and $\mathrm{m} / \mathrm{z}$ model were used for automated peak integration in XCalibur software package (Thermo Scientific, Austin, TX, USA).

\subsection{Analysis of non-volatile polar metabolites by ${ }^{1} \mathrm{H} N M R$ spectroscopy}

For ${ }^{1} \mathrm{H}$ NMR analysis, the samples from two replicates were prepared according to the method previously described (Settachaimongkon et al., 2014a). NOESY 1D- ${ }^{1} \mathrm{H}$ NMR measurements were performed in a $600 \mathrm{MHz}$ NMR spectrometer (Bruker, Rheinstetten, Germany) operated with similar parameters as described by Lu et al. (2013). The ${ }^{1} \mathrm{H}$ NMR spectra were baselinecorrected, phase-corrected, aligned and calibrated based on the internal standard (TSP) peak. For each spectrum, chemical shift $(\delta)$ across the range of $0.00-10.00 \mathrm{ppm}$ was segmented (binning) with an interval of $0.02 \mathrm{ppm}$ (Settachaimongkon et al., 2014a). The signal intensity in each bin was integrated and expressed in arbitrary units using AMIX software (Bruker, Rheinstetten, Germany). Metabolite labels were assigned to the bins by means of Chenomx NMR suite 7.5 library (Chenomx Inc., Alberta, Canada) and from the list of metabolites identified by Settachaimongkon et al. (2014a). For unlabeled bins, significant variables were selected based on one-way ANOVA at 95\% confidence level.

\subsection{Statistical analysis}

ANOVA and multiple comparisons by Tukey's test were performed using IBM-SPSS statistics package version 21 (SPSS Inc., Chicago, IL, USA). A probability at $P<0.05$ was considered statistically significant. Metabolomics data were normalized before multivariate analysis (Settachaimongkon et al., 2014a). Principal component analysis was performed using Multi-Experiment Viewer (MeV) version 4.8 (www.tm4.org/mev/).

\section{Results}

\subsection{Bacterial growth and survival}

Viable counts of yoghurt starters and probiotics were enumerated during set-yoghurt fermentation and refrigerated storage (Fig. 1). Bacterial populations in the samples co-fermented with sublethally precultured LP-WCFS1 were compared with those observed in the samples co-fermented with standard precultured LP-WCFS1 (control group). The main effects of individual stress factors, i.e. elevated $\mathrm{NaCl}$ and low $\mathrm{pH}$, and their interaction were
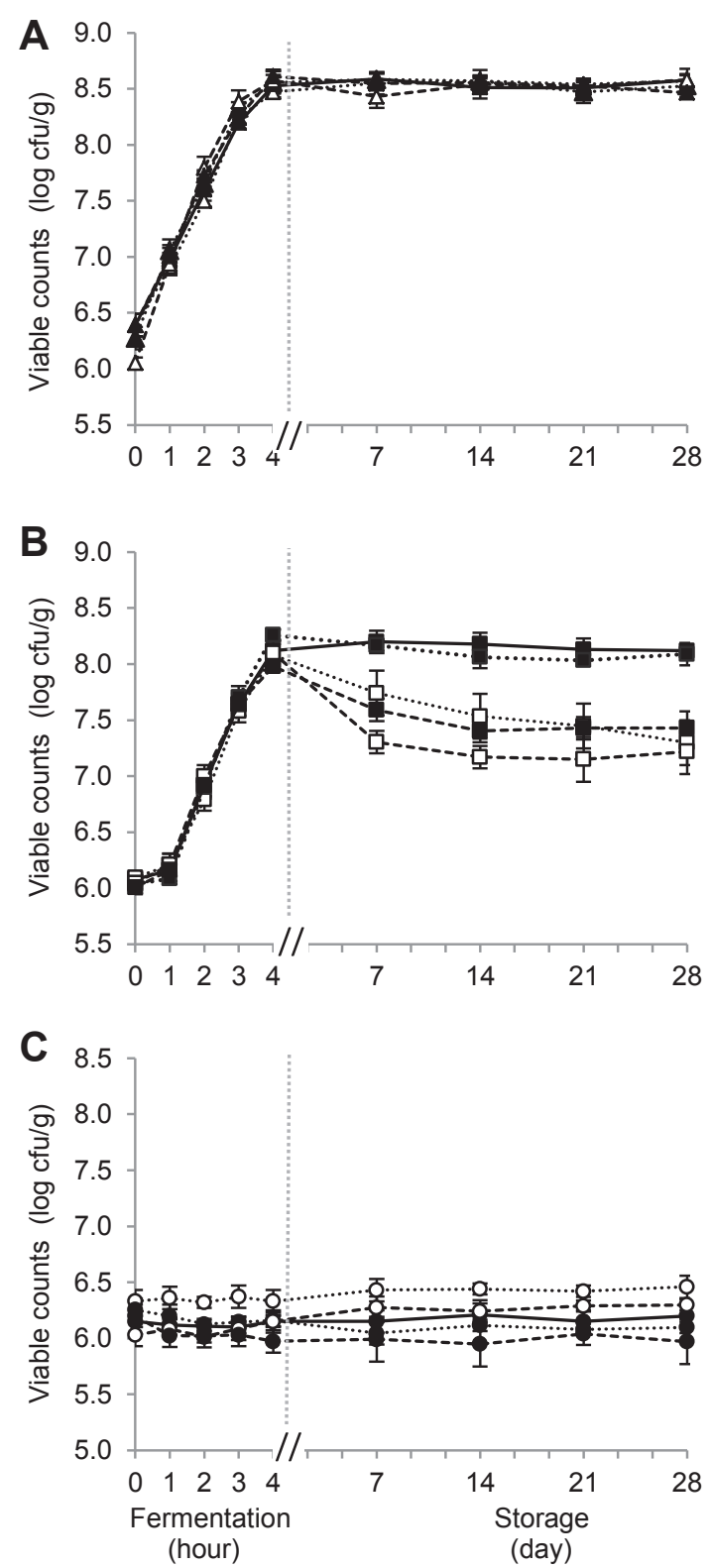

Fig. 1. Changes in viable counts of $S$. thermophilus (ST, $\Delta$; panel A), L. delbrueckii subsp. bulgaricus (LB, $\square$; panel B) and L. plantarum WCFS1 (LP, $\bigcirc$; panel C) during set-yoghurt fermentation $(4 \mathrm{~h}$ ) and refrigerated storage (28 days). Data are labeled according to the preculturing conditions of LP: standard precultured (control) group (—; black markers), LP precultured at 1.5\% NaCl-pH 4.5 (.....; white markers), $1.5 \% \mathrm{NaCl}-\mathrm{pH} 6.5$ (.....; black markers), 4.5\% NaCl-pH 4.5 (-- - ; white markers) and 4.5\% NaCl-pH 6.5 (---; black markers). Error bars represent standard deviations based on three replicates. 
Table 2

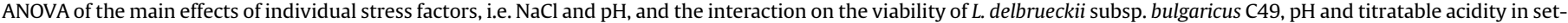
yoghurts co-fermented with $L$. plantarum WCFS1 and the precultured cells.

\begin{tabular}{|c|c|c|c|c|c|c|c|c|}
\hline \multirow[t]{3}{*}{ Measured parameter at the end of storage (28 days) } & \multirow{3}{*}{$\begin{array}{l}\text { Non-precultured } \mathrm{LP}^{\mathrm{a}} \text { (control } \\
\text { group) }\end{array}$} & \multicolumn{4}{|c|}{ Precultured LP } & \multicolumn{3}{|c|}{ Test of significant effects } \\
\hline & & \multicolumn{2}{|l|}{$1.5 \% \mathrm{NaCl}$} & \multicolumn{2}{|l|}{$4.5 \% \mathrm{NaCl}$} & \multicolumn{2}{|c|}{ Main effect } & \multirow{2}{*}{$\frac{\text { Interaction }}{\mathrm{NaCl}^{*} \mathrm{pH}}$} \\
\hline & & $\mathrm{pH} 4.5$ & pH 6.5 & $\mathrm{pH} 4.5$ & pH 6.5 & $\mathrm{NaCl}$ & $\mathrm{pH}$ & \\
\hline $\begin{array}{l}\text { Viable counts of L. delbrueckii subsp. bulgaricus (log } \\
\text { CFU/g) }\end{array}$ & $8.1 \pm 0.1 b^{b}$ & $7.3 \pm 0.2 \mathrm{a}$ & $8.1 \pm 0.1 b$ & $7.2 \pm 0.2 \mathrm{a}$ & $7.4 \pm 0.2 \mathrm{a}$ & $P<0.01$ & $P<0.01$ & $P=0.01$ \\
\hline $\mathrm{pH}$ value & $4.1 \pm 0.1 \mathrm{a}$ & $4.3 \pm 0.1 \mathrm{ab}$ & $4.1 \pm 0.1 \mathrm{a}$ & $4.3 \pm 0.0 \mathrm{~b}$ & $4.3 \pm 0.0 b$ & $P<0.05$ & $P<0.05$ & $P>0.05$ \\
\hline Titratable acidity (\% lactic acid) & $0.98 \pm 0.02 b$ & $0.83 \pm 0.03 a$ & $0.94 \pm 0.01 b$ & $0.77 \pm 0.02 a$ & $0.84 \pm 0.04 a$ & $P<0.05$ & $P<0.05$ & $P>0.05$ \\
\hline
\end{tabular}

a Lactobacillus plantarum WCFS1.

b Letters indicate significant difference $(P<0.05)$ among mean values within the same row.

determined using two-way ANOVA with $2 \times 2$ between subjects factorial design (Table 2).

Growth (increase in viable count during fermentation) and survival (retention in viable count during refrigerated storage) of $S$. thermophilus were not significantly affected by the incorporation of any of the LP-WCFS1 cultures (Fig. 1A). Their viable counts increased by $2.2 \log$ units to reach and average value of $8.5 \pm 0.1 \log$ $\mathrm{CFU} / \mathrm{g}$ at the end of fermentation and remained stable (above 8.0 $\log$ CFU/g) towards the end of storage. Also the growth of L. delbrueckii subsp. bulgaricus during fermentation was not affected by co-cultivation with sublethally precultured LP-WCFS1 resulting in an average value of $8.1 \pm 0.1 \mathrm{log} \mathrm{CFU} / \mathrm{g}$ at the end of fermentation. On the other hand, deviations in the survival of L. delbrueckii subsp. bulgaricus during refrigerated storage were clearly observed (Fig. 1B). The survival of $L$. delbrueckii subsp. bulgaricus was significantly impaired $(P<0.01)$ by co-cultivation with LP-WCFS1 precultured at $1.5 \% \mathrm{NaCl}-\mathrm{pH} 4.5$ and $4.5 \% \mathrm{NaCl}$ (with either $\mathrm{pH} 4.5$ or 6.5 ) resulting in significantly lower average viable counts $(7.2 \pm 0.2 \log \mathrm{CFU} / \mathrm{g})$ compared to the control group $(8.1 \pm 0.1 \log \mathrm{CFU} / \mathrm{g})$ at the end of storage. The main effects of $\mathrm{NaCl}$ and $\mathrm{pH}$ as well as their interaction accounted on sublethally precultured LP-WCFS1 cells provided an indirectly adverse effect on the stability of $L$. delbrueckii subsp. bulgaricus during storage (Table 2). Although none of the LP-WCFS1 cultures used in this study could grow in milk during fermentation, these bacteria demonstrated very good stability in set-yoghurt during refrigerated storage (Fig. 1C). The viable counts of standard precultured LPWCFS1 and all sublethally precultured cells remained virtually stable from the beginning of fermentation throughout the entire duration of storage (ca. $6.2 \pm 0.1 \log \mathrm{CFU} / \mathrm{g}$ ).

\subsection{Acidification profiles}

Changes in $\mathrm{pH}$ were monitored during set-yoghurt fermentation and refrigerated storage (Fig. 2A). Similar pH decrease patterns were observed during fermentation in all yoghurt samples regardless of the types of preculturing of the LP-WCFS1 culture, resulting in an average $\mathrm{pH}$ value of $4.5 \pm 0.1$ at the end of fermentation. During refrigerated storage, co-fermentation with standard precultured LP-WCFS1 and LP-WCFS1 precultured at 1.5\% $\mathrm{NaCl}-\mathrm{pH} 6.5$ demonstrated similar $\mathrm{pH}$ decrease pattern resulting in a final $\mathrm{pH}$ value of $4.1 \pm 0.0$. On the other hand, deviations in the reduction of $\mathrm{pH}$ were observed in the samples co-fermented with LP-WCFS1 precultured at $1.5 \% \mathrm{NaCl}-\mathrm{pH} 4.5$ and $4.5 \% \mathrm{NaCl}$ (with either $\mathrm{pH} 4.5$ or 6.5 ) resulting in an average $\mathrm{pH}$ value of $4.3 \pm 0.1$ at the end of storage. Although this variation appeared to be small, statistical tests demonstrated a significant difference $(P=0.02)$ compared to the control group. The main effects of $\mathrm{NaCl}$ and $\mathrm{pH}$ (without interaction) contributed significantly $(P<0.05)$ to the final $\mathrm{pH}$ of yoghurt samples (Table 2 ).
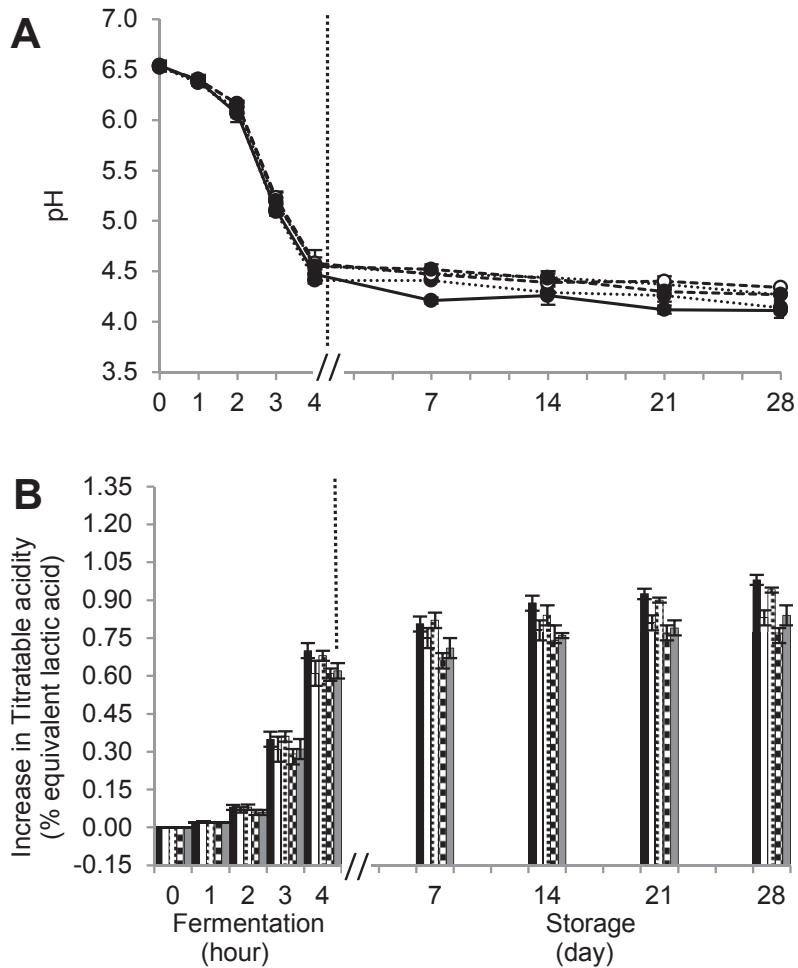

Fig. 2. Changes in $\mathrm{pH}$ (panel $\mathrm{A}$ ) and titratable acidity (panel B) during fermentation (4 h) and refrigerated storage (28 days) in set-yoghurts co-fermented with $L$. plantarum WCFS1 (LP) and their stress-adapted cells. Data are labeled according to the preculturing conditions of LP; i.e. standard precultured (control) group ( $\longrightarrow$, $\mathbf{\square})$, LP

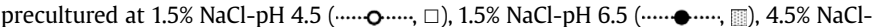
pH 4.5 (---o--, \&) and 4.5\% NaCl-pH 6.5 (------, $\square)$. Error bars represent standard deviations based on three replicates.

The titratable acidity, expressed as \% equivalent lactic acid ( $\mathrm{w} /$ $\mathrm{w}$ ), was subtracted by its initial value in the sample at $0 \mathrm{~h}$ (unfermented milk) and presented as titratable acidity produced by bacterial activity (Fig. 2B). The result did not show significant difference in titratable acidity among yoghurt samples at the end of fermentation $(0.64 \pm 0.04 \%)$, with one exception. A lower acid production during storage was observed in the samples cofermented with LP-WCFS1 precultured at $1.5 \% \mathrm{NaCl}-\mathrm{pH} 4.5$ and $4.5 \% \mathrm{NaCl}$ (with either $\mathrm{pH} 4.5$ or 6.5 ). These cultures resulted in a significant lower titratable acidity $(0.81 \pm 0.04 \%)(P=0.01)$ compared to the control group $(0.96 \pm 0.03 \%)$. The two main effects of $\mathrm{NaCl}$ and $\mathrm{pH}$ (without interaction) accounted on stress-adapted LP-WCFS1 cells contributed significantly $(P<0.05)$ on the difference in titratable acidity among yoghurt samples at the end of storage (Table 2). This result is in agreement with the reduction of $\mathrm{pH}$ previously observed. 

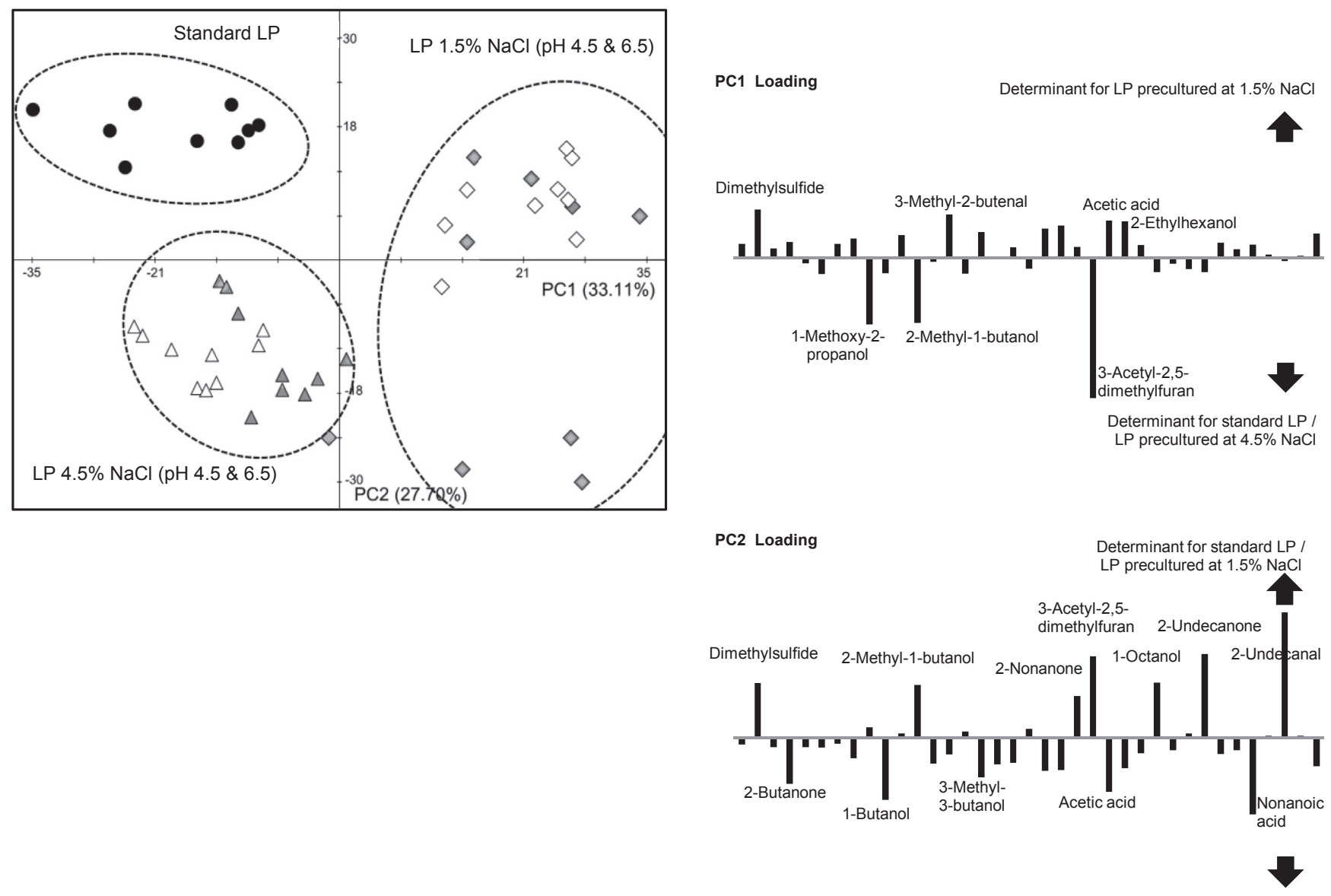

Determinant for LP precultured at $4.5 \% \mathrm{NaCl}$

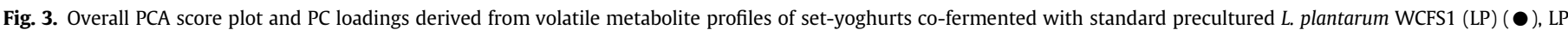
precultured at 1.5\% NaCl-pH $4.5(\diamond), 1.5 \% \mathrm{NaCl}-\mathrm{pH} 6.5(\diamond), 4.5 \% \mathrm{NaCl}-\mathrm{pH} 4.5(\Delta)$ and 4.5\% NaCl-pH $6.5(\Delta)$.

\subsection{Volatile metabolite profiles determined by headspace SPME- GC/MS}

Volatile metabolite profiles of set-yoghurts co-fermented with different types of LP-WCFS1 were evaluated at the end of fermentation $(4 \mathrm{~h})$ and every two weeks during storage (14 d and $28 \mathrm{~d}$ ) according to the method described in our previous study (Settachaimongkon et al., 2015). A total of 35 volatile metabolites consisting of alcohols, carbonyl compounds, organic acids, sulfur compounds and heterocyclic compound were identified (Table S1). These compounds were introduced as variables for multivariate analysis. Principal component analysis (PCA) was performed to distinguish the volatile metabolite profiles among set-yoghurts cofermented with standard precultured LP-WCFS1 and their sublethally precultured cells. Samples from three replicates were statistically treated as individual objects.

An overall PCA score plot was constructed with a total explained variance of $61 \%$ ( $n=45$ ) (Fig. 3). The result demonstrated that volatile profiles of the samples co-fermented with standard precultured LP-WCFS1 were completely different from those cofermented with (i) LP-WCFS1 precultured at $1.5 \% \mathrm{NaCl}$ (with either pH 4.5 or 6.5 ) along PC1 (33.1\% variance) and (ii) LP-WCFS1 precultured at $4.5 \% \mathrm{NaCl}$ (with either $\mathrm{pH} 4.5$ or 6.5 ) along $\mathrm{PC} 2$ (27.7\% variance). The PC-loading indicated which metabolites were accountable for discrimination. The PC1-loading indicated that dimethyl sulfide, 3-methyl-2-butenal, acetic acid and 2-ethylhexanol were the key determinant of samples co-fermented with
LP-WCFS1 precultured at $1.5 \% \mathrm{NaCl}$ while the PC2-loading indicated that 2-butanone, 1-butanol, 3-methyl-3-butanol, 3-pentanol, acetic acid, 2-ethyl-hexanol and nonanoic acid were the key determinant of samples co-fermented with LP-WCFS1 precultured at $4.5 \% \mathrm{NaCl}$. Among the indicative metabolites mentioned, acetic acid (vinegar, pungent) and 2-butanone (sweet, fruity) are two of the major compounds responsible for distinctive aroma profile of yoghurt (Cheng, 2010). These two compounds were detected in significantly higher abundance in the samples co-fermented with sublethally precultured LP-WCFS1, especially at $4.5 \% \mathrm{NaCl}$ (with either $\mathrm{pH} 4.5$ or 6.5) (Fig. 4).

\subsection{Non-volatile polar metabolite profiles determined by ${ }^{1} \mathrm{H} N \mathrm{NR}$}

For non-volatile polar metabolite profiling, NOESY-1D- ${ }^{1} \mathrm{H}$ NMR spectra of set-yoghurts were processed according to the method described previously (Settachaimongkon et al., 2014a). A total of 43 metabolites including amino acids, carbohydrates, organic acids, lipid derivatives, carbonyl compounds, a sulfur compound and a nucleoside were identified. The quantification was achieved by summation of signal intensities in all bins corresponding to the respective metabolite (Park et al., 2013) and expressed in $\log _{10}$ transformed values (arbitrary unit) (Table S2). For multivariate analysis, it should be noted that the 43 identified metabolites accounted for labeling of 149 bins. A complementary data filtering by ANOVA was performed for selection of the remaining unknowns (Lamanna et al., 2011). Finally, a total of 266 bins were introduced 


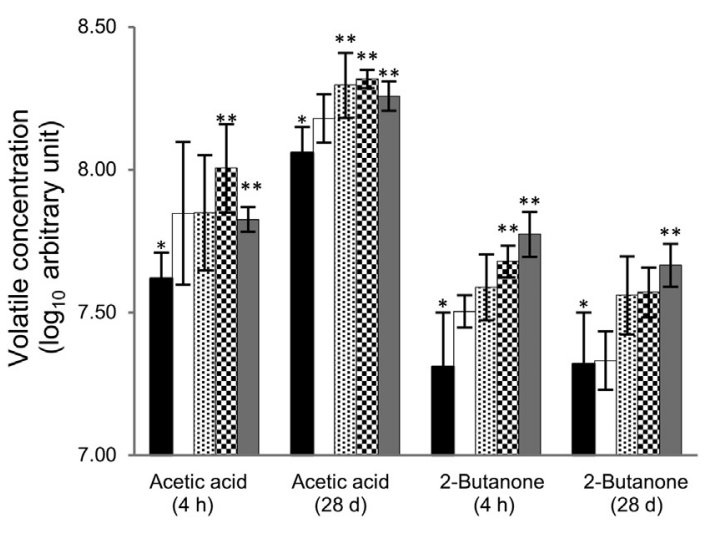

Fig. 4. Quantity of acetic acid and 2-butanone present in set-yoghurts co-fermented with standard precultured $L$. plantarum WCFS1 (LP) ( $\boldsymbol{\square})$, LP precultured at $1.5 \% \mathrm{NaCl}-$

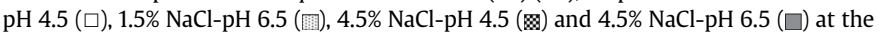
end of fermentation $(4 \mathrm{~h})$ and the end of storage (28 days). Error bars represent standard deviations based on three independent replicates. $\left(^{*}\right)$ indicates significant differences among mean values $(P<0.05)$ of specific compound quantified in samples at the same time point.

as variables in the analysis.

An overall PCA score plot was constructed with a total explained variance of $43 \%$ ( $n=20$ ) (Fig. $5 \mathrm{~A})$. The result demonstrated that non-volatile polar metabolite profiles of the samples co-fermented with LP-WCFS1 precultured at $1.5 \% \mathrm{NaCl}$ (with either $\mathrm{pH} 4.5$ or 6.5 ) could be well distinguished from those of LP-WCFS1 precultured at $4.5 \% \mathrm{NaCl}$ (with either $\mathrm{pH} 4.5$ or 6.5 ) and standard precultured LPWCFS1 along PC1 (30.3\% variance). The PC1-loading indicated that the majority of metabolites contributed to the separation of the two latter groups. However, a clear distinction between the samples cofermented with standard precultured LP-WCFS1 and LP-WCFS1 precultured at $4.5 \% \mathrm{NaCl}$ (with either $\mathrm{pH} 4.5$ or 6.5 ) was not observed. Thus, an additional PCA score plot was constructed with a total variance of $36.2 \%(n=12)$ (Fig. 5B). The result revealed that the samples co-fermented with standard precultured LP-WCFS1 could be distinguished from those of LP-WCFS1 precultured at $4.5 \% \mathrm{NaCl}$ (with either $\mathrm{pH} 4.5$ or 6.5 ) along PC3 (9.5\% variance).

\section{Discussion}

During yoghurt production, high acidity, shifts in osmotic pressure stress and application of additives are among the main environmental factors encountered by probiotics (Mohammadi et al., 2012). Combinations of these stress factors were employed during preculturing of LP-WCFS1 in a batch fermentor. Furthermore, it has been reported that stress responses vary depending on the growth phase of LAB, i.e. cells in stationary phase develop more general resistance to various types of stresses compared to cells in the exponential growth phase (Saarela et al., 2004). Therefore, the preculturing in this study was prolonged for $24 \mathrm{~h}$ to obtain stressadapted LP-WCFS1 cells, harvested in the stationary phase.

The vigorous growth and good retention of survival of S. thermophilus C44 and L. delbrueckii subsp. bulgaricus C49 during set-yoghurt fermentation and refrigerated storage have been discussed previously (Settachaimongkon et al., 2014b). In co-cultures with potential probiotic LP-WCFS1, it was interesting to see that the survival of $L$. delbrueckii subsp. bulgaricus during refrigerated storage was significantly impaired by co-culturing with LP-WCFS1 precultured at $1.5 \% \mathrm{NaCl}-\mathrm{pH} 4.5$ and $4.5 \% \mathrm{NaCl}$ (with either $\mathrm{pH}$ 4.5 or 6.5 ). On the other hand, there was no adverse effect observed on the survival of $S$. thermophilus. A proposed explanation for this is that sublethal preculturing may trigger the synthesis of certain compounds in stress-adapted LP-WCFS1 which provide inhibitory effect on L. delbrueckii subsp. bulgaricus. Many members of LAB are known to produce peptides or proteins with antimicrobial activity, i.e. bacteriocins, to improve their competitiveness against closely related species (Jack et al., 1995). Bacteriocins produced by different strains of $L$. plantarum, i.e. plantaricins, have been identified and characterized (da Silva Sabo et al., 2014; Olasupo, 1996). It has been documented that environmental factors, e.g. sugar, $\mathrm{NaCl}, \mathrm{pH}$ and temperature, play an important role in regulation of bacteriocin production in L. plantarum (Leal-Sánchez et al., 2002; Olasupo, 1996). Moreover, induction of bacteriocin production by coculturing with a range of bacterial strains, including yoghurt starters, appeared to be a common feature in L. plantarum (Li et al., 2015; Maldonado-Barragán et al., 2013). The LP-WCFS1 genome provided evidence for the presence of genes ( $p l n$ genes) encoding plantaricin synthesis (Kleerebezem et al., 2003; Siezen and van Hylckama Vlieg, 2011). Although the native state of LP-WCFS1 was found to be a bacteriocin negative strain, Sturme et al. (2007) reported that its bacteriocin production could be induced. Plantaricins produced by LP-WCFS1 showed activity against closely related species which can be found in the same ecological niches (Sturme et al., 2007). The adverse effect of stress-adapted LPWCFS1 on the survival of $L$. delbrueckii subsp. bulgaricus found in this study is an interesting observation, possibly explained by induced plantaricins production but requiring further investigation to deliver direct evidence for the involvement of this bacteriocin.

Regarding the effect of sublethal preculturing on growth and survival of LP-WCFS1, there was no significant difference observed among the standard precultured LP-WCFS1 and the sublethally precultured cells. None of preculturing conditions applied in this study could enhance the growth of LP-WCFS1 during set-yoghurt fermentation. The limited capacity of $L$. plantarum to grow in milk is explained by its weak proteolytic activity (Georgieva et al., 2009). This observation corresponds with our previous study on L. rhamnosus GG and B. animalis subsp. lactic BB12 in which we also did not manage to find a suitable preculturing condition for successful growth improvement of probiotics in milk (Settachaimongkon et al., 2015). However, unlike L. rhamnosus GG and $B$. animalis subsp. lactic BB12, all cultures of LP-WCFS1 exhibited extremely good survival in set-yoghurt. Their populations remained virtually stable from the starting point of fermentation throughout the entire duration of storage. This observation is in agreement with the work of Mirlohi et al. (2014) who found that survival of L. plantarum A7 in yoghurt was irrelevant to milk acidification. High survival of various strains of L. plantarum in fermented milk has also been reported (Georgieva et al., 2009; Maragkoudakis et al., 2006; Mirlohi et al., 2014). Furthermore, the genome sequence of LP-WCFS1 provided insight on how this LAB strain may have adapted to growth in diverse environmental niches such as fermented foods, plants, and the human gastrointestinal tract (Kleerebezem et al., 2003). Indeed, it should be mentioned that the final viable counts of LP-WCFS1 and the sublethally precultured cells in this study remained above the minimum recommended level (6.0 log CFU/g) to ensure their potential health-promoting effects (Shiby and Mishra, 2013). This information makes LP-WCFS1 a good candidate probiotic strain for yoghurt production.

A significantly higher $\mathrm{pH}$ and lower titratable acidity were observed at the end of storage in the samples co-fermented with LP-WCFS1 precultured at $1.5 \% \mathrm{NaCl}-\mathrm{pH} 4.5$ and LP-WCFS1 precultured at $4.5 \% \mathrm{NaCl}$ (with either $\mathrm{pH} 4.5$ or 6.5 ). Although the variation in final $\mathrm{pH}$ appeared to be small, yoghurt samples could be categorized into different product segments: (i) mild $\left(\mathrm{pH}_{28 \mathrm{~d}}>4.30\right)$ for those co-fermented with LP-WCFS1 precultured at $1.5 \% \mathrm{NaCl}-\mathrm{pH}$ 4.5 and $4.5 \% \mathrm{NaCl}$ (with either $\mathrm{pH} 4.5$ or 6.5 ) and (ii) semi-mild 

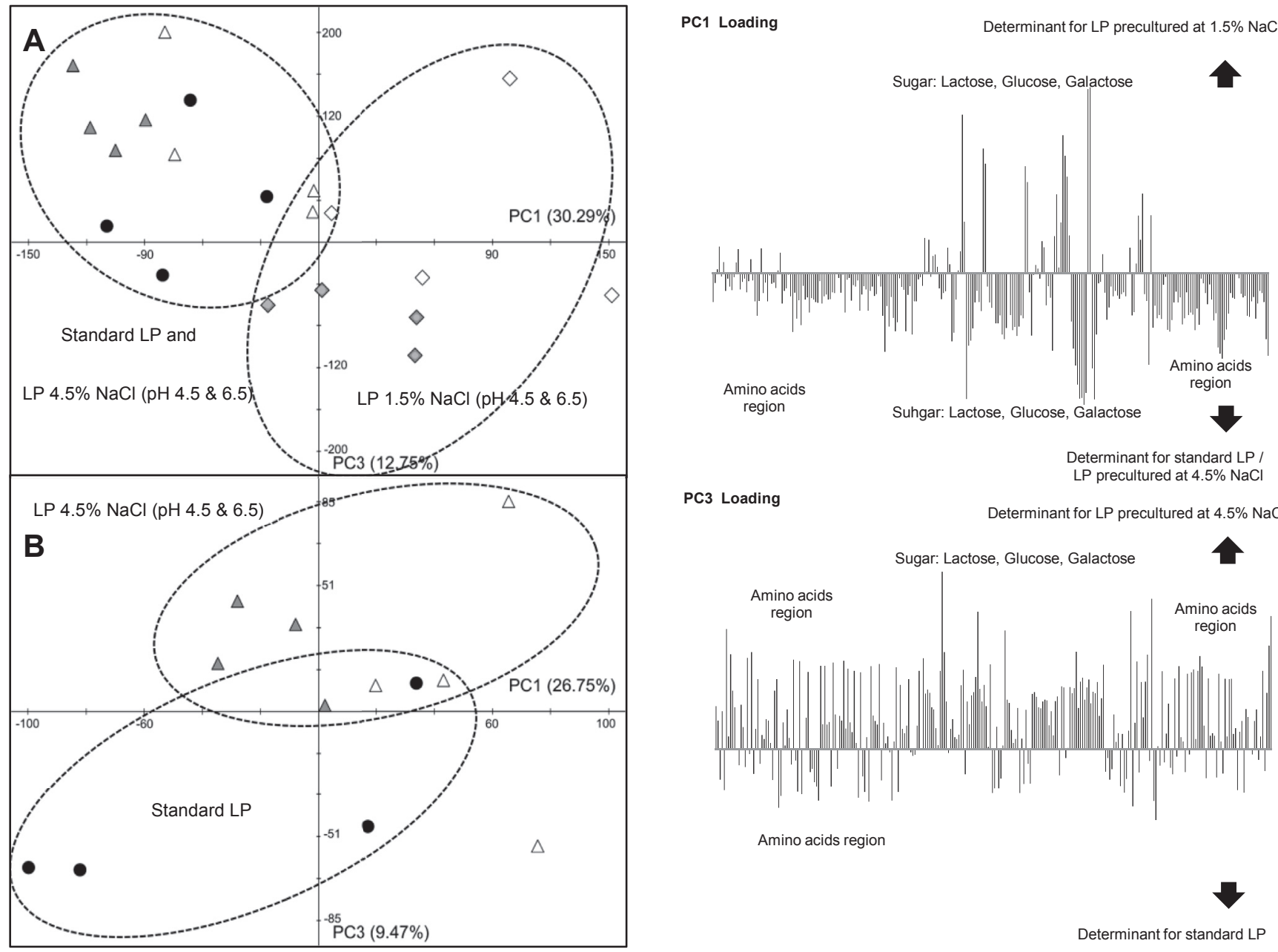

PC3 Loading

LP precultured at $4.5 \% \mathrm{NaCl}$

Determinant for LP precultured at $4.5 \% \mathrm{NaCl}$

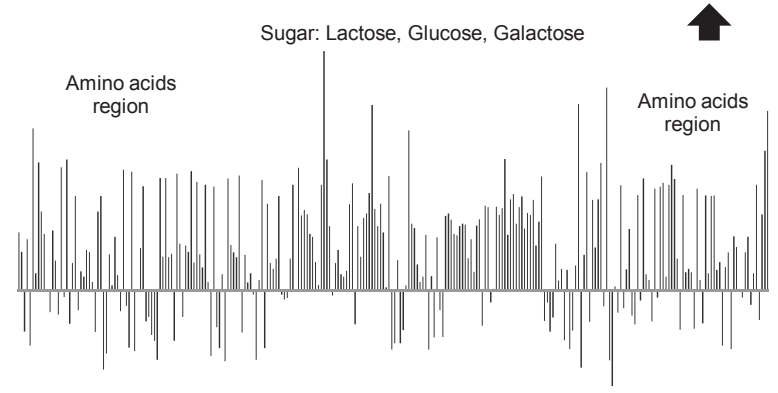

Amino acids region

Determinant for standard LP

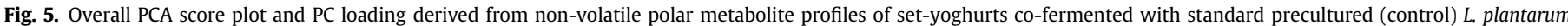

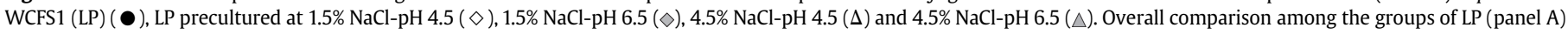
and comparison between standard precultured LP and LP precultured at $4.5 \% \mathrm{NaCl}$ (panel B) are respectively presented.

$\left(4.00<\mathrm{pH}_{28 \mathrm{~d}}<4.25\right)$ for those co-fermented with standard precultured LP-WCFS1 and LP-WCFS1 precultured at 1.5\% NaCl-pH 6.5 according to the information provided by yoghurt starters supplier (CSK, 2013). The reduction of $\mathrm{pH}$ and accumulation of organic acids during refrigerated storage of fermented milk are defined as "postacidification" which is mainly attributed to the ongoing metabolic activity of L. delbrueckii subsp. bulgaricus (Shah, 2000). With respect to this, the significantly lower post-acidification observed in setyoghurts co-fermented with sublethally precultured LP-WCFS1 could be associated with the decrease in viable counts of L. delbrueckii subsp. bulgaricus as discussed previously.

Adaptive stress responses in LAB are associated with the modification of various physiological features (Van de Guchte et al., 2002). The development of cellular protective mechanisms in lactobacilli induced by acid and osmotic stress have been discussed in our previous study (Settachaimongkon et al., 2015). In short, acid stress induces physiological adaptation known as acid tolerance response (ATR) for the induction of $\mathrm{pH}$ homeostasis, whereas osmotic stress results in the accumulation of compatible solutes and activation of membrane associated proteins for maintaining turgor pressure of the cell (Serrazanetti et al., 2009; Van de Guchte et al., 2002). Recently, genes encoding different stress-related proteins have been identified in the genome of $L$. plantarum WCFS1 (Kleerebezem et al., 2003). Adaptation to stress induces alterations in the metabolic activity of bacterial cells leading to substantial changes in their technological and functional performances (Serrazanetti et al., 2009; Siragusa et al., 2014). As a result, a broader variety of metabolites can be formed which may considerably influence the biochemical characteristics of the fermented product (Serrazanetti et al., 2009). PCA patterns observed in this study confirm the impact of incorporation of sublethally precultured LPWCFS1 on the metabolome of yoghurt. Relating to the adverse effect on the survival of L. delbrueckii subsp. bulgaricus and significant decrease in post-acidification mentioned previously, a distinction between metabolite profiles of the samples co-fermented with LPWCFS1 precultured at $1.5 \% \mathrm{NaCl}-\mathrm{pH} 4.5$ and $\mathrm{pH} 6.5$ was expected. However, PCA results revealed that volatile and non-volatile metabolite profiles of the samples co-fermented with these two cultures were relatively close to each other. This observation suggests that only the effect of $\mathrm{NaCl}$ accounted on stress-adapted LPWCFS1 cells predominantly contributes to the distinctive metabolome of set-yoghurt.

The effect of traditional yoghurt starters and various L. plantarum strains on production of volatile aroma compounds and non-volatile metabolites in fermented milk has been documented (Cheng, 2010; de Bok et al., 2011; Randazzo et al., 2007; Routray and Mishra, 2011). Regarding the influence of sublethal preculturing, a higher production of acetic acid and higher alcohols 
derived from catabolism of pyruvate and various amino acids was reported to be associated with the ATR in lactobacilli (Serrazanetti et al., 2009). Loading plots derived from PCA indicated that dimethyl sulfide, 3-methyl-2-butenal, acetic acid, 2-ethyl-hexanol, 2-butanone, 1-butanol, 3-methyl-3-butanol and nonanoic acid were the major metabolites contributing to discriminate volatile profiles of the samples co-fermented with sublethally precultured LP-WCFS1. Besides this, lactobacilli have systems for accumulating compatible solutes, i.e. glycine-betaine, carnitine, proline and glutamate, for maintaining turgor pressure of the cell against osmotic stress (Van de Guchte et al., 2002). According to the quantification of non-volatile metabolites (Table S2), a lower concentration of pyruvate and proline were clearly observed in the samples co-fermented with sublethally precultured LP-WCFS1. Taking into account the adverse effect on post-acidification, variations in these aroma volatile, especially acetic acid and 2-butanone, as well as non-volatile metabolites may considerably influence the organoleptic quality of product. Furthermore, it is possible that the metabolic activity of LP-WCFS1 and its sublethally precultured cells may result in an undesirable sensory profile of yoghurt, since this potential probiotic strain was originally isolated from a non-dairy environment (Kleerebezem et al., 2003). Therefore, a research focusing on sensory evaluation of yoghurt with trained panelists is essentially required.

\section{Conclusions}

This study provides relevant information on the technological implications of the use of untreated and sublethally precultured LPWCFS1. Although LP-WCFS1 showed poor capacity to grow in milk, its viable counts remained stable in set-yoghurt throughout the entire duration of refrigerated storage. The presence of standard LPWCFS1 did not influence the growth and survival of yoghurt starters as well as acidification profile of product. This finding makes LP-WCFS1 a good probiotic candidate for yoghurt manufacture. Interestingly, incorporation of LP-WCFS1 precultured at $1.5 \% \mathrm{NaCl}-\mathrm{pH} 4.5$ and $4.5 \% \mathrm{NaCl}$ (with either pH 4.5 or 6.5 ) significantly impaired the survival of $L$. delbrueckii subsp. bulgaricus during refrigerated storage. This consequently provided a significant reduction of post-acidification.

\section{Acknowledgements}

This research was conducted under CHE-PhD-SFR-2551 scholarship granted by the Commission on Higher Education of the Royal Thai Government. Yoghurt starters were kindly provided by Bert Hafkamp from CSK Food Enrichment. L. plantarum WCFS1 was obtained from TI Food and Nutrition, Wageningen, The Netherlands. The authors are grateful to Dr Kasper Hettinga, Geert Meijer, Dr Elsa Antunes Fernandes and Dr Jacques Vervoort for assistance in GC/MS and NMR analysis. We also thank Maciek Spus, Liu Yuhan, Anastasia Emelianova and $\mathrm{Wu} \mathrm{Qu}$ for technical contributions.

\section{Appendix A. Supplementary data}

Supplementary data related to this article can be found at http:// dx.doi.org/10.1016/j.fm.2016.04.008.

\section{References}

Bron, P.A., Wels, M., Bongers, R.S., van Bokhorst-van de Veen, H., Wiersma, A. Overmars, L., Marco, M.L., Kleerebezem, M., 2012. Transcriptomes reveal genetic signatures underlying physiological variations imposed by different fermentation conditions in Lactobacillus plantarum. PLoS One 7.

Cheng, H., 2010. Volatile flavor compounds in yogurt: a review. Crit. Rev. Food Sci
Nutr. 50, 938-950.

CSK., 2013. CSK Food Enrichment: Yoghurt Application Brochure V2.0-13. http:/ www.cskfood.com/assets/uploads/documents/CSK_yoghurt_EN_V2.0-13 kleinstebestandsgrootte.pdf.

da Silva Sabo, S., Vitolo, M., González, J.M.D., Oliveira, R.P.D.S., 2014. Overview of Lactobacillus plantarum as a promising bacteriocin producer among lactic acid bacteria. Food Res. Int. 64, 527-536.

de Bok, F.A.M., Janssen, P.W.M., Bayjanov, J.R., Sieuwerts, S., Lommen, A., van Hylckama Vlieg, J.E.T., Molenaar, D., 2011. Volatile compound fingerprinting of mixed-culture fermentations. Appl. Environ. Microbiol. 77, 6233-6239.

de Vries, M.C., Vaughan, E.E., Kleerebezem, M., de Vos, W.M., 2006. Lactobacillus plantarum: survival, functional and potential probiotic properties in the human intestinal tract. Int. Dairy J. 16, 1018-1028.

FAO/WHO, 2002. Guidelines for the Evaluation of Probiotics in Food: Report of a Joint FAO (Food and Agriculture Organization of the United Nations)/WHO (World Health Organization) Working Group on Drafting Guidelines for the Evaluation of Probiotics in Food, vol. 2013. FAO, London Ontario, Canada.

Georgieva, R., Iliev, I., Haertlé, T., Chobert, J.-M., Ivanova, I., Danova, S., 2009. Technological properties of candidate probiotic Lactobacillus plantarum strains. Int. Dairy J. 19, 696-702.

Gueimonde, M., Delgado, S., Mayo, B., Ruas-Madiedo, P., Margolles, A., de los ReyesGavilán, C.G., 2004. Viability and diversity of probiotic Lactobacillus and Bifidobacterium populations included in commercial fermented milks. Food Res. Int. 37, 839-850.

Hettinga, K.A., van Valenberg, H.J.F., Lam, T.J.G.M., van Hooijdonk, A.C.M., 2009. The origin of the volatile metabolites found in mastitis milk. Vet. Microbiol. 137, 384-387.

Jack, R.W., Tagg, J.R., Ray, B., 1995. Bacteriocins of gram-positive bacteria. Microbiol. Rev. 59, 171-200.

Kleerebezem, M., Boekhorst, J., Van Kranenburg, R., Molenaar, D., Kuipers, O.P., Leer, R., Tarchini, R., Peters, S.A., Sandbrink, H.M., Fiers, M.W.E.J., Stiekema, W. Klein Lankhorst, R.M., Bron, P.A., Hoffer, S.M., Nierop Groot, M.N., Kerkhoven, R., De Vries, M., Ursing, B., De Vos, W.M., Siezen, R.J., 2003. Complete genome sequence of Lactobacillus plantarum WCFS1. Proc. Natl. Acad. Sci. U. S. A. 100, 1990-1995.

Lamanna, R., Braca, A., Di Paolo, E., Imparato, G., 2011. Identification of milk mixtures by ${ }^{1} \mathrm{H}-\mathrm{NMR}$ profiling. Magn. Reson. Chem. 49, S22-S26.

Leal-Sánchez, M.V., Jiménez-Díaz, R., Maldonado-Barragán, A., GarridoFernández, A., Ruiz-Barba, J.L., 2002. Optimization of bacteriocin production by batch fermentation of Lactobacillus plantarum LPCO10. Appl. Environ. Microbiol. 68, 4465-4471.

Li, C., Chen, Y., Kwok, L.Y., Chen, X., Yu, H., Yang, H., Yang, J., Xue, J., Sun, T., Zhang, H., 2015. Identification of potential probiotic Lactobacillus plantarum isolates with broad-spectrum antibacterial activity. Dairy Sci. Technol. 95, 381-392.

Lourens-Hattingh, A., Viljoen, B.C., 2001. Yogurt as probiotic carrier food. Int. Dairy J. $11,1-17$.

Lu, J., Antunes Fernandes, E., Paez Cano, A.E., Vinitwatanakhun, J., Boeren, S., van Hooijdonk, T., van Knegsel, A., Vervoort, J., Hettinga, K.A., 2013. Changes in milk proteome and metabolome associated with dry period length, energy balance, and lactation stage in postparturient dairy cows. J. Proteome Res. 12, 3288-3296.

Maldonado-Barragán, A., Caballero-Guerrero, B., Lucena-Padrós, H., Ruiz-Barba, J.L., 2013. Induction of bacteriocin production by coculture is widespread among plantaricin-producing Lactobacillus plantarum strains with different regulatory operons. Food Microbiol. 33, 40-47.

Maragkoudakis, P.A., Miaris, C., Rojez, P., Manalis, N., Magkanari, F., Kalantzopoulos, G., Tsakalidou, E., 2006. Production of traditional Greek yoghurt using Lactobacillus strains with probiotic potential as starter adjuncts. Int. Dairy J. 16, 52-60.

Mirlohi, M., Soleimanian-Zad, S., Dokhani, S., Sheikh-Zeinodin, M., 2014. Microbial and physiochemical changes in yoghurts containing different Lactobacillus delbrueckii subsp. bulgaricus strains in association with Lactobacillus plantarum as an adjunct culture. Int. J. Dairy Technol. 67, 246-254.

Mohammadi, R., Sohrabvandi, S., Mohammad-Mortazavian, A., 2012. The starter culture characteristics of probiotic microorganisms in fermented milks. Eng. Life Sci. 12, 399-409.

Olasupo, N.A., 1996. Bacteriocins of Lactobacillus plantarum strains from fermented foods. Folia Microbiol. 41, 130-136.

Park, S.J., Hyun, S.H., Suh, H.W., Lee, S.Y., Sung, G.H., Kim, S.H., Choi, H.K., 2013. Biochemical characterization of cultivated Cordyceps bassiana mycelia and fruiting bodies by ${ }^{1} \mathrm{H}$-nuclear magnetic resonance spectroscopy. Metabolomics 9, 236-246.

Piras, C., Marincola, F.C., Savorani, F., Engelsen, S.B., Cosentino, S., Viale, S. Pisano, M.B., 2013. A NMR metabolomics study of the ripening process of the Fiore Sardo cheese produced with autochthonous adjunct cultures. Food Chem. $141,2137-2147$

Randazzo, C.L., De Luca, S., Todaro, A., Restuccia, C., Lanza, C.M., Spagna, G., Caggia, C., 2007. Preliminary characterization of wild lactic acid bacteria and their abilities to produce flavour compounds in ripened model cheese system. J. Appl. Microbiol. 103, 427-435.

Ricciardi, A., Parente, E., Guidone, A., Ianniello, R.G., Zotta, T., Sayem, S.M.A., Varcamonti, M., 2012. Genotypic diversity of stress response in Lactobacillus plantarum, Lactobacillus paraplantarum and Lactobacillus pentosus. Int. J. Food Microbiol. 157, 278-285.

Routray, W., Mishra, H.N., 2011. Scientific and technical aspects of yogurt aroma and 
taste: a review. Compr. Rev. Food. Sci. Food Saf. 10, 208-220.

Saarela, M., Rantala, M., Hallamaa, K., Nohynek, L., Virkajärvi, I., Mättö, J., 2004 Stationary-phase acid and heat treatments for improvement of the viability of probiotic lactobacilli and bifidobacteria. J. Appl. Microbiol. 96, 1205-1214.

Saccaro, D.M., Hirota, C.Y., Tamime, A.Y., de Oliveira, M.N., 2011. Evaluation of different selective media for enumeration of probiotic micro-organisms in combination with yogurt starter cultures in fermented milk. Afr. J. Microbiol. Res. 5, 3901-3906.

Serrazanetti, D.I., Guerzoni, M.E., Corsetti, A., Vogel, R., 2009. Metabolic impact and potential exploitation of the stress reactions in lactobacilli. Food Microbiol. 26, $700-711$.

Settachaimongkon, S., Nout, M.J.R., Antunes Fernandes, E.C., Hettinga, K.A., Vervoort, J.M., van Hooijdonk, T.C.M., Zwietering, M.H., Smid, E.J., van Valenberg, H.J.F., 2014a. Influence of different proteolytic strains of Streptococcus thermophilus in co-culture with Lactobacillus delbrueckii subsp. bulgaricus on the metabolite profile of set-yoghurt. Int. J. Food Microbiol. 177, 29-36.

Settachaimongkon, S., Nout, M.J.R., Antunes Fernandes, E.C., van Hooijdonk, A.C.M., Zwietering, M.H., Smid, E.J., van Valenberg, H.J.F., 2014b. The impact of selected strains of probiotic bacteria on metabolite formation in set-yoghurt. Int. Dairy J. $38,1-10$.

Settachaimongkon, S., van Valenberg, H.J.F., Winata, V., Wang, X., Nout, M.J.R., van Hooijdonk, T.C.M., Zwietering, M.H., Smid, E.J., 2015. Effect of sublethal preculturing on the survival of probiotics and metabolite formation in set-yoghurt. Food Microbiol. 49, 104-115.

Shah, N.P., 2000. Probiotic bacteria: Selective enumeration and survival in dairy foods. J. Dairy Sci. 83, 894-907. http://dx.doi.org/10.3168/jds.S0022-0302(00) 74953-8.

Shah, N.P., 2007. Functional cultures and health benefits. Int. Dairy J. 17, 1262-1277.
Shiby, V.K., Mishra, H.N., 2013. Fermented milks and milk products as functional foods: a review. Crit. Rev. Food Sci. Nutr. 53, 482-496.

Siezen, R.J., Tzeneva, V.A., Castioni, A., Wels, M., Phan, H.T.K., Rademaker, J.L.W., Starrenburg, M.J.C., Kleerebezem, M., Molenaar, D., Van Hylckama Vlieg, J.E.T. 2010. Phenotypic and genomic diversity of Lactobacillus plantarum strains isolated from various environmental niches. Environ. Microbiol. 12, 758-773.

Siezen, R.J., van Hylckama Vlieg, J.E.T., 2011. Genomic diversity and versatility of Lactobacillus plantarum, a natural metabolic engineer. Microb. Cell Fact. 10.

Siezen, R.J., Francke, C., Renckens, B., Boekhorst, J., Wels, M., Kleerebezem, M., van Hijum, S.A.F.T., 2012. Complete resequencing and reannotation of the Lactobacillus plantarum WCFS1 genome. J. Bacteriol. 194, 195-196.

Siragusa, S., De Angelis, M., Calasso, M., Campanella, D., Minervini, F., Di Cagno, R. Gobbetti, M., 2014. Fermentation and proteome profiles of Lactobacillus plantarum strains during growth under food-like conditions. J. Proteom. 96, 366-380.

Sturme, M.H.J., Francke, C., Siezen, R.J., de Vos, W.M., Kleerebezem, M., 2007. Making sense of quorum sensing in lactobacilli: a special focus on Lactobacillus plantarum WCFS1. Microbiology 153, 3939-3947.

Upadrasta, A., Stanton, C., Hill, C., Fitzgerald, G., Ross, R.P., 2011. Improving the stress tolerance of probiotic cultures: recent trends and future directions. In: Tsakalidou, E., Papadimitriou, K. (Eds.), Stress Responses of Lactic Acid Bacteria. Springer, New York, pp. 395-438.

Van de Guchte, M. Serror, P., Chervaux, C., Smokvina, T., Ehrlich, S., Maguin, E. 2002. Stress responses in lactic acid bacteria. Ant. Van Leeuwenhoek 82 $187-216$.

Vasiljevic, T., Shah, N.P., 2008. Probiotics: from metchnikoff to bioactives. Int. Dairy J. 18, 714-728. 